\title{
DE LA METAFÍSICA POR VENIR
}

Carlos Gutiérrez Lozano*

\section{El libro que presentamos, ${ }^{1}$ una reela-} boración de la tesis doctoral del autor, puede ser considerado, por un lado, como una fascinante y muy amplia introducción al pensamiento filosófico del jesuita canadiense Bernard Lonergan y, por el otro, la presentación de las líneas generales de cómo debería hacerse metafísica en adelante, sobre todo en estos tiempos nuestros, llamados "posmetafísicos".

Dice nuestro autor que Lonergan no es un pensador muy conocido en general y menos aún en el ámbito hispanoparlante. Por ello este libro es una contribución muy valiosa para impulsar el pensamiento lonerganeano en nuestro país y en Latinoamérica. ${ }^{2}$

Las 485 páginas de la obra están distribuidas en un prefacio, un prólogo de Philip McShane (un estudioso mundialmente reconocido del pensamiento de Lonergan), una introducción, ocho capítulos, dos anexos, las conclusiones, la bibliografía y muchas, muchas notas, no a pie de página, sino al final del respectivo apartado, lo cual me parece horrible, pero se soporta por la muy valiosa información que contienen.

* Departamento Académico de Estudios Generales, ITAM.

${ }^{1}$ Francisco Vicente Galán Vélez, Una metafísica para tiempos posmetafísicos. La propuesta de Bernard Lonergan de una metametodología, 2015, México, Universidad Iberoamericana, $485 \mathrm{pp}$.

${ }^{2}$ Francisco Galán coordina el grupo de estudio Lonergan Latinoamérica, que ya ha realizado tres talleres latinoamericanos en 2011, 2013 y 2015. Puede consultarse la página electrónica en $<$ www.lonerganlat.org $>$. 
El libro deja ver claramente que su autor es un auténtico profesor y filósofo: de un profundo y muy amplio saber, tanto de la filosofía como de la ciencia, la historia y el sentido común (¿de qué otra manera podría alguien presentar a un pensador que estudió filosofía, teología, matemáticas, economía y ciencias naturales en Montreal, Oxford, Londres y Roma?), junto con una capacidad extraordinaria para transmitir, en este caso por escrito, sus conocimientos, una marcada sensibilidad pedagógica (igual que en Insight de Lonergan) y una consumada capacidad para crear un clima de confianza de modo que el lector se integre al diálogo, a la discusión y al trabajo por venir.

Los primeros capítulos, empezando por la introducción, atrapan inmediatamente al lector, y el capítulo sobre Verbum es espectacular. Después baja un poco la intensidad, pues los capítulos comentan "nada más" la estructura de Insight para ahondar nuevamente en las profundizaciones de Método en teología, la metafísica del ser trascendente y las conclusiones.

En la introducción se describe el lugar desde el cual el pensamiento de Lonergan quiere ser presentado como significativo: la posmodernidad. Para nuestro autor, "vivimos en una cultura altamente diferenciada y mínimamente integrada [...] Una integración que nos permita formar comunidad y que se enriquezca de las diferencias parece cada vez más una tarea imposible" (p. 25). La propuesta metafísica de Lonergan es actual y pertinente porque permite "buscar una nueva integración que respete y no anule las diferencias" (p. 29). Una ciencia que sea capaz de lo anterior solo puede ser concebida como una metametodología, una meta-ciencia y una meta-hermenéutica. La finalidad del libro es mostrar que la metafísica, tal como la propone Lonergan, es precisamente esa ciencia, pero no una ciencia que ya está realizada como un cuerpo doctrinal, sino una ciencia en cuanto estructura y dinamismo de la mente humana.

Los puntos que más se destacan de la labor filosófica de Lonergan son la introducción de la historia en la teología, y también en la metafísica, la primacía (pedagógica) de la teoría del conocimiento y el pronunciado carácter pedagógico o preparativo de su propuesta. 
Lonergan se entiende dentro de la tradición aristotélico-tomista, pero no es un dócil discípulo que repite a la letra la doctrina del maestro, sino que se ha adueñado de la mente del Estagirita y del Aquinate; es decir, ha asimilado de su propia estructura cognoscitiva y por eso puede entender lo que ellos entendieron. Las diferencias y semejanzas con esta tradición están condensadas en la siguiente afirmación: "La metafísica sigue siendo considerada como ciencia, o mejor quizás metaciencia, pero no en conformidad con la idea aristotélica de ciencia; y por controlar sus significados desde una teoría de las operaciones cognoscitivas, puede tener, como sus elementos básicos, términos o categorías plenamente explicativos y no meramente descriptivos" (p. 35). La metafísica de Lonergan quiere hacer justicia a las exigencias actuales que, según Habermas, son el pensamiento posmetafísico, el giro lingüístico y el primado de la práctica sobre la teoría. ${ }^{3}$ Igualmente quiere mantenerse que la metafísica no pertenece al pasado, sino que está latente en el dinamismo cognoscitivo de cada ser humano, y por ello tiene también la "tarea negativa de destrucción de falsos ídolos, enajenaciones y abstracciones" (p. 39). De este modo, la metafísica de Lonergan no puede ser una metafísica de doctrinas o de conceptos, sino de nociones heurísticas, es decir, anticipadoras. En palabras de nuestro autor: "Una metafísica 'nocional' es ante todo la propuesta de un método, de una praxis, de una acción, en este caso de la acción de conocer, de la praxis cognoscitiva de los seres humanos [...] La metafísica es pues una metametodología. Un trabajo permanente y más bien grupal" (p. 41). Finalmente, Galán informa que la exposición de la metafísica de Lonergan la hace queriendo dialogar con cuatro autores considerados, cada uno a su manera, antimetafísicos: Kant, Heidegger, Nietzsche y Wittgenstein. Considero que la confrontación con Kant y Heidegger es amplia y lograda, señalando afinidades y divergencias. La confrontación con Nietzsche es marginal, mientras que con Wittgenstein se dio una paradoja, pues el autor afirma: "sin poder presentar un diálogo con los detalles que el tema lo [sic] exigiría, en el presente trabajo se hace un

${ }^{3}$ Menciona cuatro, pero solo desarrolla tres. Al parecer une la razón situada con el primado de la práctica. 
intento de dialogar mayormente con esta tradición" (p. 49). En efecto, se intentó, pues incluso hay un excurso sobre el particular, pero el diálogo no terminó por cuajar. Un límite del trabajo por lo anunciado y una oportunidad para el autor en el futuro.

El primer capítulo, repetimos, es espectacular. Presenta paso a paso la apropiación que Lonergan hizo de la mente de Aristóteles y de Santo Tomás por medio de su estudio sobre el verbum como analogía trinitaria. Al hilo de la exposición de estos artículos queda claro que Insight ya estaba prácticamente contenida en esta primera investigación. Galán apunta, en efecto, que aquí se vislumbra un núcleo fundamental de toda la obra lonerganeana, a saber: "el control semántico de los términos metafísicos desde el lenguaje de la intencionalidad o de la interioridad" (p. 60). Y es que Lonergan descubre que tanto el Estagirita como el Aquinate ejercitaron la psicología introspectiva, pero no la llevaron a término. Por ello se insiste varias veces en el libro que la filosofía de Lonergan, en la estela de Aristóteles y Tomás, es "un gran rechazo al conceptualismo" (p. 62), el cual consiste en "tener conceptos o afirmaciones sin entendimiento" (p. 66). Aquí queda claro por qué para Lonergan la primacía "pedagógica" la tiene siempre la teoría del conocimiento y el dinamismo de la mente humana. Aristóteles y Tomás entienden el acto de conocer como identidad (y no como confrontación) y esto significa que conocemos por lo que somos y no por lo que hacemos. Para ambos el juicio es una síntesis o composición que se pone de manera absoluta, lo cual hace pensar necesariamente en Kant y en la famosa digresión de si Lonergan es un tomista trascendental en la estela de Maréchal. Finalmente, ambos señalan que "la naturaleza de la verdad es peculiar, pues si bien nadie la posee plenamente, nadie está totalmente fuera de ella; se necesita la colaboración de los seres humanos para lograr éxito en la búsqueda de la verdad" (p. 82). De ahí que Lonergan conciba la metafísica como una gran tarea grupal. Todo esto le hace afirmar a Lonergan, y esto será lo que desarrolle ampliamente en Insight, que "la clave de la psicología tomista está en captar lo que es entender, entender los propios actos de entender" (p. 88). Al descubrir con Tomás el rango virtualmente infinito de nuestro intelecto, Lonergan 
entiende que el ser no puede ser una noción común, sino que es de un orden específico. Aquí está ya contenida la noción heurística del ser. Las conclusiones de Galán acerca de Verbum de Lonergan son: "he aquí claramente esbozada la tesis de la circularidad entre lo que se llama 'psicología introspectiva' y la metafísica [...] la metafísica es la expresión de un sujeto inteligente [...] lo ontológico y lo cognoscitivo no son alternativas incompatibles, sino procedimientos interdependientes" (p. 96).

El segundo capítulo presenta la arquitectura de Insight: veinte capítulos divididos en la preparación (1-10), los fundamentos (11-13), la expansión (14-18) y la transformación de la metafísica (19-20). A Lonergan le interesan aquí cuatro cosas. La primera es la naturaleza concreta del conocimiento, y por ello pretende "pasar de un tipo de reflexión sobre el ser humano dominado por la idea de naturaleza humana, atemporal, universal y abstracta a otro dominado por el gran énfasis moderno de la conciencia” (p. 109). En este capítulo se aborda la importancia de los niveles de conciencia: experiencia, entendimiento, juicio y deliberación; los patrones de experiencia (biológico, estético, dramático, artístico, religioso, intelectual y práctico) y el famoso polimorfismo de la conciencia, todos tan recurrentes a lo largo del libro. Lonergan declara como normativo el patrón intelectual de conciencia. Esto es muy importante, puesto que "Lonergan insistirá una y otra vez que conocer no es ver, sino experimentar, entender y juzgar” (p. 115).

En segundo lugar le interesa la estructura de lo conocido. Esto apunta a lo heurístico. Para Lonergan, "el problema es quedarse con lo conocido como algo abstracto, estático, no generado históricamente y olvidar el carácter dinámico, procesual, temporal y, con todo, estructurado de manera necesaria" (p. 117). El tercer punto de interés es la apropiación, de manera paulatina, a través de un desarrollo continuado, de nuestra conciencia intelectual y racional, es decir, experimentar, entender y juzgar nuestros actos de experiencia, entendimiento y juicio. Lonergan realiza muchos ejercicios para ayudar al lector a conseguir la autoapropiación, pero también señala la importancia fundamental de los sesgos que impiden el conocimiento y el autoconocimiento y esto 
lleva a confrontarnos con el misterio de lo humano: no siempre queremos entender. Con todo, en el juicio, que implica un insight reflejo, llegamos a la autoapropiación de nuestra conciencia racional.

En cuarto lugar, tenemos que el desarrollo debe ser paulatino y ganado con esfuerzo. Lonergan se mueve de las matemáticas a la ciencia y al sentido común, familiarizándonos con las estructuras heurísticas clásicas y estadísticas, de modo que el lector pueda ir captando y afirmando su propio dinamismo cognoscitivo. En el excurso introduce Galán la misteriosa idea lonerganeana de cosmópolis: "La cosmópolis pide una ciencia humana crítica que asuma los retos de la complejidad y se esfuerce por ser inteligente y razonable" (p. 134).

El tercer capítulo ofrece el núcleo de Insight, es decir, la autoapropiación del sujeto cognoscente, confrontándola con otros intentos de fundamentación como Descartes o Kant (Lonergan supera a Kant por medio de Kant, como ya lo había sugerido Maréchal), la noción heurística (anticipadora) del ser, la cual es equivalente al deseo puro e irrestricto de conocer, es decir, que el ser es lo conocido y lo que queda por conocer, y la objetividad, la cual me parece que quedó prácticamente sin analizar, si bien es cierto que es un seudoproblema y que en varias partes del libro se afirma de manera implícita, pues la apropiación del sujeto cognoscente hace que la objetividad sea la coincidencia entre ser y conocer, ya que el ser es lo que se conoce cuando hacemos una afirmación verdadera. Aquí Galán solo habla de la objetividad como fidelidad a lo dado y al deseo puro de conocer ( $c f r$. p. 168), pero en el análisis de Verbum señala lo siguiente: "de modo que el problema de cómo un sujeto conoce un objeto que está afuera resulta irresoluble por ser un problema mal planteado, ya que cualquier solución que se proponga ha de suponer lo que se quiere probar, a saber, que el sujeto ya sabe qué es la realidad y por eso es capaz de plantear el problema" (p. 94). ${ }^{4}$ Galán remarca aquí que una las tareas más importantes y urgentes de la filosofía es que "las posiciones piden ser desarrolladas y las contrapo-

${ }^{4}$ Sobre la objetividad experiencial, normativa y absoluta en Lonergan, véase Carlos Gutiérrez Lozano, "La metafísica en el tomismo trascendental de Bernard Lonergan y Emerich Coreth”, Estudios, núm. 113, 2105, pp. 42-44. 
siciones piden ser revertidas". Así, la posición fundamental de Lonergan es que lo real es el universo concreto del ser, el sujeto llega a ser conocido cuando se afirma de manera inteligente y racional, la objetividad como consecuencia de la indagación inteligente y la reflexión crítica, el ser es completamente inteligible y que hay algo que escapa a nuestra inteligencia y es el residuo empírico. Las contraposiciones son contradicciones performativas, o dicho más clásicamente, argumentos ad hominem o bien argumentos por retorsión.

En el capítulo cuarto se da la definición de metafísica: "la concepción, la afirmación y la implementación de la estructura heurística integral del ser proporcionado". ${ }^{6}$ Para Lonergan, la metafísica tiene tres estadios, a saber, el latente (la estructura dinámica del conocer), el problemático (la necesidad de una sistematización) y el explícito (la definición mencionada anteriormente). La metafísica explicita debe mostrar las siguientes características: debe ser progresiva, matizada, fáctica, dependiente de la ciencia y del sentido común, estable, explicativa. Para Galán, el mérito de esta propuesta es que "a la vez que conserva los logros monumentales de un Aristóteles y un Tomás de Aquino, trata de subsanar su incapacidad de integrar los avances de la ciencia moderna" (p. 190). Esto solo es posible porque la metafísica "es un asunto de integración y de reorientación” (p. 193). En una de las notas, Galán transcribe lo que implica esta nueva comprensión de la metafísica: "una tarea monumental que solo puede realizar un grupo de personas de distintas formaciones que colaboran en una tarea conjunta con un método o meta-método. Tarea que, por lo demás, es permanente. 'Metafísica' en sentido lonerganeano nos suena a una universidad cosmopolita, ciertamente no de las de ahora, sino del viejo sueño de la Academia de Platón" (p. 223, nota 30). El método de la metafísica, que no es otro que el de la autoapropiación misma, pues esta hace que la metafísica latente devenga explícita, es llamado por Lonergan de diversas maneras: introspectivo, psicología racional, método empírico generalizado, teoría de las operaciones cognoscitivas, método que lleva a la autoapropiación ( $c f r$. p. 448). También la llamó método trascen-

${ }^{5}$ Bernard Lonergan, Insight. Un estudio sobre la comprensión humana, 1999, Salamanca, Sígueme/UIA, trad. de Francisco Quijano, p. 461.

${ }^{6}$ Ibid., p. 466. 
dental, lo cual provocó que se le considerara miembro del movimiento tomista trascendental y propició una confrontación intelectual con Emerich Coreth, a la cual Galán dedica un amplio anexo, cuya conclusión es que Lonergan acentúa más el aspecto pedagógico, por lo que las diferencias entre ellos realmente son mínimas: Galán explica que "la disputa se vuelve más bien nominal" (p. 242) o que es "solo una diferente formulación” (p. 247), ${ }^{7}$ además de aclarar que en Lonergan la influencia de Newman es mayor que la de Maréchal.

En los siguientes capítulos (quinto, sexto y séptimo) Galán profundiza en la metafísica y señala una de sus tareas fundamentales en cuanto metaciencia o metamétodo, a saber, la integración de los materiales provenientes de la ciencia, de las filosofías y de las culturas. En el capítulo quinto se hace referencia directa a la ciencia, por lo que Lonergan introduce una terminología relativamente nueva que pueda hacer justicia tanto a las ciencias (en este caso naturales) como a la metafísica. Primero habla de los componentes ontológicos de la realidad: la potencia, la forma y el acto, los cuales pueden ser tanto centrales como conjugados. Así se mantiene el isomorfismo entre el conocer (experiencia, entendimiento y afirmación racional) y lo conocido (potencia, forma y acto) y se reafirma que la inteligibilidad es intrínseca al ser, por lo que la objetividad está salvada desde el principio. En segundo lugar hace mención de los diferentes tipos de métodos (el clásico, el estadístico, el genético, el dialéctico y después todavía el crítico), los cuales señalan el grado superior de integración de materiales. En tercer lugar habla de géneros y especies explicativos que posibilitan la aparición de puntos de vista superiores. Para Galán, este tema es muy importante porque "permite explicar cómo pueden coexistir e integrarse las distintas ciencias sin que se viole la autonomía relativa de cada una" (p. 265). Así, la física es un género explicativo y la química otro, pero esta es un punto de vista superior con respecto a aquella; la biología es un nuevo género superior a la química y así sucesivamente. En cuarto lugar se habla del dinamismo finalístico tanto de la actividad cognoscitiva como del universo del ser proporcionado. Para Lonergan,

${ }^{7}$ Véase Gutiérrez Lozano, op. cit., pp. 27-65. 
el universo es un dinamismo orientado, indeterminado (no se puede predecir), realista, universal, matizado y flexible. Por tanto, "se puede aprehender que la dirección del dinamismo de la finalidad consiste en una realización efectivamente probable de posibilidades" (p. 274), en otras palabras: un "universo incompleto dirigiéndose hacia un ser más completo” (p. 275). ¡La comparación de esta comprensión de la finalidad con la physis griega es muy emocionante! El método genético subraya la dimensión del desarrollo, tan importante en la ciencia desde el siglo XIX, si bien matiza en una nota que "el método genético es pertinente solo para los seres vivos y en la vida existen los tres desarrollos, que no son similares. El estudio de los seres vivos sigue siendo en gran parte descriptivo y poco explicativo" (p. 295, nota 38).

En el sexto capítulo se presenta la metafísica como semántica básica para poder hacer las equivalencias entre las proposiciones metafísicas y las científicas. Es el capítulo menos logrado del libro, si bien es cierto que estamos hablando del punto más conflictivo y difícil de la metafísica en cuanto metametodología. Aquí encontramos afirmaciones sobre la unidad del universo y sobre las dimensiones del ser humano, y se destaca su control inteligente de la vida sensible. Lonergan llama "“espiritual' a la inteligibilidad que es inteligente" (p. 324), y por ello el hombre es material y espiritual. Los métodos clásico, estadístico, genético y dialéctico pueden y deben integrarse.

Se presenta en el capítulo séptimo a la metafísica como integradora de los saberes de las filosofías y de las culturas (esto es, del sentido común); por ello, puede entenderse la metafísica como dialéctica universal, no en sentido hegeliano. Aquí la metafísica es "hermenéutica metódica de las filosofías” (p. 338). Si esto es así, entonces la metafísica tiene que ver con el mito y con el misterio, pues ambas son formas de integración de saberes. Este capítulo ofrece una complementación importante, pues la autoapropiación hace referencia al individuo como si este estuviera aislado y pudiera lograrla por sí mismo, sin ninguna ayuda o referencia externa; pero no es así. El sujeto que se autoapropia es un miembro de una sociedad, de una cultura. "El autoconocimiento se da siempre en el contexto de una comunidad de la que el sujeto es parte 
integrante; por ello, el desarrollo de un conocimiento adecuado involucra, como su condición de posibilidad, ciertos desarrollos culturales en la ciencia, la filosofía y estos, a su vez, necesitaron de cierto desarrollo en el lenguaje e, incluso, en los sistemas económicos y políticos" (p. 341). Lonergan comparte la definición clásica de verdad como adecuación entre el intelecto y la cosas, pero subraya que hay una triple apropiación de la misma: cognoscitiva (reconocerla como tal), volitiva (querer vivir conforme a ella) y sensitiva (adaptar nuestra sensibilidad a los requerimientos de nuestro conocimiento). Lonergan propone un punto de vista universal como criterio hermenéutico, lo cual parece simplemente imposible, pues un punto de vista es, por definición, particular y no universal. Pero Lonergan recuerda que tal punto es heurístico, es decir, anticipador y siempre en dinamismo.

En el capítulo octavo se analiza la relación entre Insight y Método en teología. Insight es un punto de vista en movimiento que obviamente también puede propiciar un punto de vista superior. Esto sucede al agregarse el nivel de la decisión responsable y el nivel de la ayuda divina frente al mal en el mundo. En Método ya no se habla de apropiación, sino de conversión. Esta es "un cambio de horizonte" (p. 387) pues el horizonte es "lo que permite percibir objetos" (p. 387). La conversión puede ser intelectual, moral o religiosa y "no se trata solo de encontrar más y mejor; se trata de cambiar el criterio de lo que es encontrar y de cómo se encuentra ese algo" (p. 388). En Método se insiste sobre todo en las ocho especialidades funcionales como profundización de la tarea de la metafísica, pues ilustra claramente que el trabajo es inmenso, imposible de abarcar para una persona. Habla del progreso como el desarrollo de los imperativos trascendentales: sé atento, sé inteligente, sé razonable, sé responsable. La decadencia sería lo contrario. Como se trata de interactuar y colaborar entre unos y otros, el tema de la significación se vuelve nuevamente relevante, ahora profundizando en sus funciones: la comunicativa y la constitutiva, las cuales dan lugar a las nociones clave de comunidad (conjunto de individuos) existencia (individuo identificado con su comunidad) e historia (tejido de comunidades e individuos). Las especialidades funcionales son ocho: cuatro históricas 
(investigación de los datos, interpretación, historia y dialéctica) y cuatro sistemáticas (establecer los fundamentos, establecer las doctrinas, sistematización y comunicación). El aporte original de nuestro autor es que las especialidades funcionales, si bien pensadas solo para la teología, podrían ser utilizadas igualmente en la filosofía. De ahí su propuesta de que la tarea pendiente de la metafísica es hacer Método en filosofia.

En el anexo II sobre el ser trascendente se habla un poco de la ética y de la teología natural lonerganeanas. Lonergan señala el peligro de entender la trascendencia como algo espacial, pues es más bien "el asunto de suscitar nuevas preguntas" (p. 418). Además, la fuente de la trascendencia es el ya mencionado deseo de conocer, por ser prácticamente infinito. Lonergan elabora su propia prueba o vía de la existencia de Dios como el incondicionado formal, como el contenido de un acto de conocer irrestricto. Finalmente, ante el problema del mal, Lonergan presenta la probabilidad emergente de lo sobrenatural como solución no humana, pues la fe, la esperanza y la caridad pueden ser concebidas como formas conjugadas $\mathrm{y}$, por tanto, reales.

Las conclusiones remarcan el carácter metodológico, heurístico de la metafísica en confrontación con los intentos anteriores. Para Galán, la propuesta de Lonergan es "una fundamentación fuerte de la filosofía primera, a la vez que un programa abierto al futuro de la filosofía" (p. 444). Y señala nuevamente que la metafísica es algo por hacerse y que, por la dimensión de las tareas de revisar posiciones y contraposiciones y de integrar tanto métodos como contenidos de las ciencias, la historia y el sentido común de las diferentes culturas, es algo que solo puede ser hecho por un grupo a lo largo de mucho tiempo y con cierta madurez en los individuos para la colaboración eficaz, la cual pide, a su vez, una transformación de las instituciones como las conocemos actualmente (¿una velada crítica al actual sistema por competencias que domina en la mayoría de las universidades?). 
